to rapid deterioration of the latter. These repeated changes appeared to affect the mites adversely and were no doubt responsible for the apparent retardation in development.

Similar data have been accumulated for male mites. Their total development period was about $0 \cdot 6$ day less than that of the females over the whole temperature-range.

This work is being extended into the lower temperature-ranges and special attention is to be paid to the effects of the considerable diurnal temperaturerange experienced under glass.

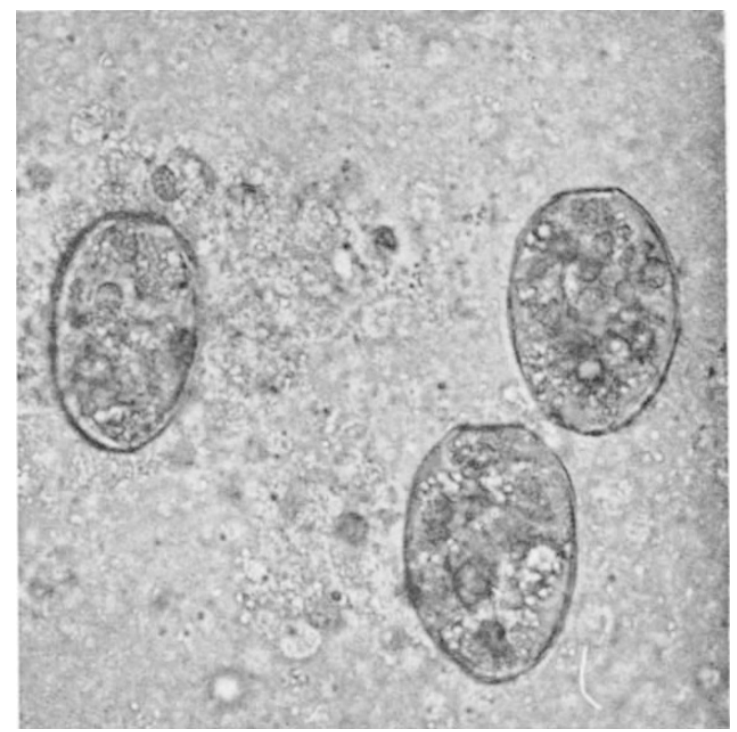

N. W. HusseY

W. J. PARR

Glasshouse Crops Research Institute, C. D. CROCKER

Worthing Road,

Rustington, Littlehampton. Jan. 14.

1 Van Marle, G. S., Spintbestrijding. Proofstation, Aalsmeer, Holland (1951).

2 Linke, W., Höfchen. Briefe, 6 (4), 182 (1953).

soudreaux, H. B., Ann. Ent. Soc. Amer., 49, 43 (1956),

- Callan, E. McC., Nature, 160, 432 (1947).

\title{
A New Trematode, Poikilorchis congolensis, n.g., n.sp., living in Subcutaneous Retroauri- cular Cysts in Man from the Belgian Congo
}

Yarwood and Elmes ${ }^{1}$ observed a cyst in the retroauricular region of a native in Nigeria, containing operculated eggs having the same form as the eggs of Paragonimus. Recently, one of us discovered, in natives of the Kasai Province, four cases of cysts or abscesses, similarly situated and containing eggs resembling those of Paragonimus westermani but slightly smaller in size ${ }^{2}$. Examination of an adult worm extracted from one of these cysts showed that it did not belong to the Troglotrematidae (although it had some of the characteristics of this family) but to the Achillurbainiidae Dollfus ${ }^{3}$. At the present time this family is represented by only one genus containing one species Achillurbainia nouveli Dollfus, which was discovered in an abscess of the upper eyelid in a Malayan leopard. Our specimen has certain differences from the genus Achillurbainia and we propose to place it in a new genus and in a new species : Poïkilorchis congolensis n.g., n.sp.

The worm is brown (in formalin), flattened, $7.6 \mathrm{~mm}$. long and $3.9 \mathrm{~mm}$. wide; oral sucker terminoventral and smaller than the acetabulum, which is situated about one-third of the distance along the body; cuticle non-spinous and non-scaly. The prepharynx is absent, pharynx well developed, œsophagus dorsoventral and very short; the cæca reach about the end of the body and have very numerous folds. The excretory vesicle is I-shaped and slightly widened anteriorly. The ovary is ovoid, regular in shape and not lobate, situated to the left of the median line, a little behind the acetabulum; uterus contains numerous eggs, lying between the two cæca, the posterior border of the ovary and the acetabulum; receptaculum seminis small, bilobate, situated medially; testes very numerous (about two hundred) and very irregular in shape, situated in the posterior two-thirds of the body; seminal vesicle large, situated in front of the acetabulum; cirrus pouch and copulatory organ absent; genital pore situated in front of the acetabulum a little to the right of the median line ; vitellaria very numerous

Fig. 1. Eggs of Poikilorchis congolensis n.g., n.sp., found in a retroauricular cyst

filling almost all the body ; eggs operculated, without a spine opposite the operculum, $0.063 \mathrm{~mm}$. long and $0.04 \mathrm{~mm}$. wide (Fig. 1).

This new genus is distinguished from the genus Achillurbainia by the following characters : testes very irregular in shape, cæca having very numerous and short folds, receptaculum testis small, bilobate and median, genital pore paramedian, ovary ovoid.

It is notable that none of the four patients from Kasai suffered from pulmonary paragonimiasis and did not have eggs in the sputum. However, two of these patients were inhabitants of villages where so-called pulmonary paragonimiasis had been previously observed. Considering the dimensions of the eggs found in a case reported by Libert in the Cameroons ${ }^{4}$, we think that it is probable that some of the cases reported as pulmonary paragonimiasis in Africa are in fact caused by this new parasite.

A. FAIN

J. VANDEPITTE

Provincial Medical Laboratory of Kivu, Bukavu, and

Provincial Medical Laboratory of Kasai,

Luluabourg,

Belgian Congo. Jan. 11.

1 Yarwood, G. R., and Elmes, B. G., Trans. Roy. Soc. Trop. Med. Hyg., 36, 347 (1943).

2 Vandepitte, J., et al. (in the press).

${ }^{3}$ Fain, A., and Vandepitte, J., (in the press).

${ }^{4}$ Libert, C., West African Med. J., 5, 51 (1932).

\section{An Interchange Heterozygote in Vicia faba}

DURING cytological investigations into the action of ethyleneimines upon root-tip cells of Vicia faba, variety Sutton's Seville Long Pod, one treated seedling was found in which all dividing cells possessed a chromosome complement differing from that of the normal seedlings. Observations and measurements of the chromosome complement, carried out on eight metaphase cells from normal seedlings, showed that it was possible to recognize, apart from pairs 3 and 4 , 